\title{
Ambrisentan for the treatment of pulmonary arterial hypertension
}

\author{
Brian Casserly ${ }^{1,3}$ \\ James R Klinger ${ }^{2,3}$ \\ 'Division of Pulmonary Medicine, \\ The Memorial Hospital of Rhode \\ Island, Pawtucket, RI, USA; ${ }^{2}$ Division \\ of Pulmonary Sleep and Critical Care \\ Medicine, Rhode Island Hospital; \\ ${ }^{3}$ Waren Alpert Medical School of \\ Brown University, Providence, RI, USA
}

Correspondence: James R Klinger Division of Pulmonary Sleep and Critical Care Medicine, Rhode Island Hospital, 593 Eddy Street, Providence, RI 02903

Tel + I 40I 4442776

Fax +I 40I 4443002

Email james_klinger@brown.edu

\begin{abstract}
Ambrisentan is an endothelin receptor antagonist (ERA) that was recently approved for treatment of pulmonary arterial hypertension (PAH). Endothelin (ET) is a potent vasoconstrictor with mitogenic, hypertrophic and pro-inflammatory properties that is upregulated in pulmonary hypertensive diseases. The biologic effects of ET are mediated by 2 cell surface receptors termed $\mathrm{ET}_{\mathrm{A}}$ and $\mathrm{ET}_{\mathrm{B}}$. $\mathrm{ET}_{\mathrm{A}}$ mediates the vasoconstrictor effect of $\mathrm{ET}$ on vascular smooth muscle, whereas $\mathrm{ET}_{\mathrm{B}}$ is expressed primarily on vascular endothelial cells where it induces nitric oxide synthesis and acts to clear ET from the circulation. Ambrisentan is the first $\mathrm{ET}_{\mathrm{A}}$ selective ERA approved for use in the US. Recently published clinical trials in patients with PAH demonstrate improvement in functional capacity and pulmonary hemodynamics similar to other $\mathrm{ET}_{\mathrm{A}}$ selective and non-selective ERAs. Its once daily dosing and lower incidence of serum aminotransferase elevation offer potential advantages over other ERAs, but further experience with this agent is needed to fully understand its long-term efficacy and safety. This review discusses the endothelin family of proteins and receptors and their role in the pathophysiology of pulmonary hypertensive diseases. It also examines the development process, safety profile and clinical trials that have resulted in ambrisentan being approved for treatment of PAH.
\end{abstract}

Keywords: ambrisentan, endothelin receptor antagonist, pulmonary hypertension, endothelin

\section{Pulmonary hypertension}

Pulmonary arterial hypertension (PAH) is a disease of the small pulmonary arteries that is characterized by vasoconstriction and vascular remodeling (Humbert et al 2004b). In particular, hypertrophy and proliferation of pulmonary vascular smooth muscle results in thickening of the medial wall of mid sized pulmonary arteries and muscularization of more peripheral normally non-muscularized vessels (Tuder et al 2001). Marked proliferation of endothelial cells in distal pulmonary arterials is also evident and in some areas causes near obliteration of the vascular lumen or tortuous remodeling with evidence of recanulized channels (plexiform lesions). This remodeling of the pulmonary vascular bed substantially reduces the cross sectional area of the pulmonary vascular tree (Tuder et al 2007). At the same time, pulmonary vascular tone may be increased and the ability of the pulmonary circulation to dilate or recruit underutilized vessels in response to increased flow is reduced (Chan and Loscalzo 2008). These changes result in a progressive increase in pulmonary vascular resistance (PVR) that increases right ventricular afterload, reduces exercise tolerance and in most cases results in right ventricular failure (Granton and Moric 2008).

Over the last 13 years, 6 drugs comprising 3 different drug classes have been approved for the treatment of PAH in the US (Table 1). All 6 drugs have been shown to decrease pulmonary arterial pressure, albeit to a minor degree, improve cardiac output and exercise capacity over a 3 to 4 month period and several have been shown to prolong survival compared to historical controls (Torres 2007; Gomberg-Maitland 
Table I Current medications approved for the treatment of pulmonary arterial hypertension

\begin{tabular}{lllll}
\hline Generic name & Trade name & Drug class & Administration routes & Date approved \\
\hline $\begin{array}{llll}\text { Epoprostenol } \\
\text { Treprostinil }\end{array}$ & Flolan & Prostacyclin analogue & Continuous IV infusion & 1995 \\
Iloprost & Remodulin & Prostacyclin analogue & Continuous IV or SQ infusion & 2002 (SQ) 2004 (IV) \\
Ventavis & Prostacyclin analogue & $\begin{array}{l}\text { Nebulized inhalation } \\
\text { 6-9 times daily }\end{array}$ & 2004 \\
Bosentan & Tracleer & Non-selective endothelin & Oral twice daily & 200 I \\
Ambrisentan & Letairis & $\begin{array}{l}\text { Receptor antagonist } \\
\text { Selective endothelin }\end{array}$ & Oral once daily & 2007 \\
Sitaxsentan & Receptor antagonist & Oral once daily & 2006 (Europe, Canada) \\
Sildenafil & Selective endothelin & Receptor antagonist & Oral thrice daily & 2005 \\
Beraprost & Revatio & Phosphodiesterase & Oral I to 3 times per day & 1994 (Japan) \\
\hline
\end{tabular}

and Olschewski 2008). However, none of these drugs has been able to consistently reverse PAH or prevent disease progression and most are too recently developed to determine their long-term effect on survival. Furthermore, some of the more effective therapies are difficult to use due to adverse effects or the need for continuous infusion or frequent inhalation (Gomberg-Maitland and Olschewski 2008). Hence, there remains a strong need to enhance or expand therapeutic options presently available to combat $\mathrm{PAH}$.

The endothelins are a family of compounds composed of a similar 21 amino acid structure that have potent vasoconstrictor properties and proliferative effects on pulmonary vascular smooth muscle and endothelial cells (Janakidevi et al 1992). In addition, endothelin (ET) has hypertrophic effects on cardiac myocytes (Schiffrin 2005) and important profibrotic and pro-inflammatory effects on a variety of cell types (Guarda et al 1993; Mullol et al 1996). Data suggesting a role of the endothelins in the pathophysiology of PAH include elevated circulating levels of endothelin-1 (ET-1) in patients with PAH and increased expression of ET-1 in plexiform lesions (Matsui et al 2002) occluding the distal pulmonary arteries of PAH patients. Clinical studies have also shown a strong inverse relationship between plasma ET-1 levels and survival in patients with PAH (Franz et al 2008). As a consequence, there has been an intense interest in manipulation of endothelin signaling as therapeutic approach to PAH (Jeng et al 2002; Battistini et al 2006). Endothelin receptor antagonists (ERAs) have become an integral part of therapy for PAH (Jacobs et al 2006) with 3 different drugs having been developed and approved for use (Table 1). Ambrisentan (LU 208075) an orally active diphenyl propionic acid derivative is the most recently developed ERA and received FDA approval in June, 2007.

\section{The endothelins}

In 1985, Hickey et al described an endothelium-derived contractile factor that was subsequently isolated and sequenced by Yanagisawa et al from porcine aortic endothelial cell cultures in 1988 and named endothelin (Hickey et al 1985; Yanagisawa et al 1988). The discovery of endothelin was rapidly followed by the realization that its release, perhaps from a dysfunctional endothelium, could have a major role in the pathogenesis of numerous vascular diseases and that pharmacological manipulation of the ET system might provide important therapeutic advances (Haynes and Webb 1992; Clozel and Roux 2000).

The endothelin (ETs) system consists of 3 identified isopeptides, named endothelin-1, -2 and -3 (ET-1, ET-2, ET-3) possessing a similar 21 amino acid structure (Masaki et al 1991). The most abundant and predominant isoform is ET-1. This peptide has unusually high and sustained vasoconstrictive activity (Clarke et al 1989). The initial observation that ET-1 vasoconstrictor activity was 10 times more potent than angiotensin II and 100 times more potent than norepinephrine quickly established its importance as a regulator of vascular tone (Yanigasawa et al 1988; Miyauchi et al 1990). Additional properties of ET-1 that implicate a significant pathogenic role in vascular remodeling as well as the pathogenesis of $\mathrm{PAH}$ include mitogenic effects on endothelial cells, smooth muscle cells, fibroblasts, and pericytes, and a hypertrophic effect on cardiac myocytes (Luscher and Barton 2000).

Sequence analysis of the cDNA encoding ET revealed that biologically active ET-1 is synthesized in a 2-step proteolytic 
process from a large precursor peptide of 200 amino acid residues called preproET-1 (Inoue et al 1989). A neutral endopeptidase (a furin-like peptidase) cleaves preproET-1 to generate a smaller, but still mostly inactive precursor termed big-ET-1, that is further converted to ET-1 by endothelinconverting enzymes (ECEs) (Hirata et al 1993; Laporte et al 1993). This conversion is physiologically important because ET-1 is about 140-fold more potent a vasoconstrictor than big-ET-1. Identification of the converting enzyme was challenging due to the small quantity of the enzyme contained in tissues (Takahashi et al 1993). The amino acid sequence of ECE was published in 1994 by 3 separate research groups (Schmidt et al 1994; Shimada et al 1994; Xu et al 1994). This enzyme was called ECE-1. In 1995, another isoform named ECE-2 was identified (Opgenorth et al 1992). ECE-2 has a different $\mathrm{pH}$ sensitivity than ECE-1(Emoto and Yanagisawa 1995). The existence of additional ECE isoforms was suspected because high levels of ET-1 have been reported in ECE-1 and ECE-2 double-knockout mice (Yanagisawa et al 2000). Now, 4 different human ECE-1 isoforms, derived from one gene by differential splicing, have been identified and termed ECE-1a, ECE-1b, ECE-1c and ECE-1( Meidan et al 2005; Klipper et al 2006). These isoforms differ in their short N-terminal cytoplasmic domains and are present in different subcellular sites (Valdenaire et al 1999). ECE-1a is abundant in endothelial cells and resides within intracellular secretory vesicles and is constitutively transported to the cell surface (Russell and Davenport 1999). By contrast, ECE-1b is located intracellularly close to the trans-Golgi networks. The precise roles of the other isoforms are unknown.

ET-1 release via a constitutive pathway is regulated principally at the level of gene transcription. Synthesis is enhanced by protein kinase $\mathrm{C}$ - and phospholipase $\mathrm{C}$-dependent pathways in response to physiological stimuli like low-shear stress, turbulent blood flow, angiotensin II, catecholamines, cardiotrophin-1, thrombin, growth factors, cytokines, free radicals, insulin, hypoxia, and shear stress (Emori et al 1991; Masaki et al 1991; Levin 1995; Love and McMurray 1996; Jougasaki et al 2002) . In contrast, the synthesis of ET-1 is inhibited by high-shear stress, nitric oxide, natriuretic peptides, heparin, and prostaglandins (Boulanger and Luscher 1990; Hu et al 1992; Yokokawa et al 1993; Prins et al 1994; Gray and Webb 1996).

Endothelial cells release ET-1 abluminally and ET-1 acts on adjacent smooth muscle as a local autocrine or paracrine factor rather than as a hormone (Wagner et al 1992). Only a minor portion of released ET-1 is detected in the plasma, suggesting that circulating levels of ET-1 represent an overflow of endogenous tissue-bound ET-1 and thus do not allow for a true estimate of ET-1 activity. Despite these limitations, studies have established that plasma ET-1 levels are increased in PAH and that pulmonary expression and release of ET-1 is increased in PAH (Stewart et al 1991). Interestingly, ET-1 is also produced by other cells, including leukocytes, macrophages, smooth muscle cells, cardiomyocytes, and mesangial cells (Luscher and Barton 2000).

ET-1 binds to 2 heptahelical G-protein-coupled receptors, named endothelin receptor-A $\left(\mathrm{ET}_{\mathrm{A}}\right)$ and endothelin receptor- $\mathrm{B}\left(\mathrm{ET}_{\mathrm{B}}\right)$. The $\mathrm{ET}_{\mathrm{A}}$ receptor binds $\mathrm{ET}-1$ and $\mathrm{ET}-2$ with greater affinity than it does ET-3, whereas the $\mathrm{ET}_{\mathrm{B}}$ receptor binds all three isoforms with equal affinity (Simonson and Dunn 1990). Both receptors are distributed in various tissues and cells, but with different levels of expression. Receptor expression is altered in some disease states making the effect of receptor blockade difficult to predict due to the wide range of functional expression within the ET system (Gregan et al 2004). In response to ligand binding, $\mathrm{ET}_{\mathrm{A}}$ receptors induce vasoconstriction and cellular proliferation through the activation of phospholipase $\mathrm{C}$ and subsequent increase of inositol triphosphate, diacylglycerol, and intracellular calcium (Pollock et al 1995). Activation of ET ${ }_{B}$ receptors on vascular smooth muscle causes vasoconstriction, whereas activation of $\mathrm{ET}_{\mathrm{B}}$ on endothelial cells stimulates the release of NO and prostacyclin, thus producing vasodilatory effects (Feger et al 1997). However, the vasodilator effects of endothelial $E_{B}$ activation are not enough to overcome the intense vasoconstrictor effect of $\mathrm{ET}_{\mathrm{A}}$ activation and the overall effect of ET-1 in most vascular beds is one of intense vasoconstriction (Seo et al 1994).

The intracellular mechanisms by which ETs induce smooth muscle contraction have not been fully elucidated (Yanagisawa et al 2000). ET-1 causes a transient increase in the intracellular concentration of free $\mathrm{Ca}^{2+}$ ions, followed by a sustained elevation of free $\mathrm{Ca}^{2+}$ ions for 30 to 60 minutes resulting in prolonged contraction (Masaki et al 1999). The transient increase represents $\mathrm{Ca}^{2+}$ ions released from the intracellular pool of free $\mathrm{Ca}^{2+}$ via activation of phospholipase C (PLC) (Miwa et al 1999). The sustained increase results from $\mathrm{Ca}^{2+}$ influx from the extracellular space. In the presence of physiological concentrations of ET-1, the $\mathrm{Ca}^{2+}$ influx is mediated by the activation of a non-selective cation channel(s) and a store-operated $\mathrm{Ca}^{2+}$ channel (SOCC).

In addition to its intense vasoconstrictor effect, ET-1 is a potent mitogen for a variety of cell types including vascular smooth muscle and cardiac myoctyes (Alberts et al 1994). The mitogenic effects of ET-1 are mediated by the activation 
of protein kinase $\mathrm{C}$ secondary to increases in diacylglycerol and intracellular calcium, which in turn stimulate the production of cytokines and growth factors (Ohlstein et al 1992). ET-1 also activates leukocytes and promotes proliferation of endothelial cells, smooth muscle cells and astrocytes, mostly via $\mathrm{ET}_{\mathrm{A}}$ receptors. In contrast, activation of $\mathrm{ET}_{\mathrm{B}}$ can induce apoptosis, probably via its release of $\mathrm{NO}$ and/or prostacyclin, although the mechanisms responsible for this effect are not well understood (Verhaar et al 1998; Niwa et al 2000).

Clearance of ET-1 occurs primarily via binding to $\mathrm{ET}_{\mathrm{B}}$, particularly in the vascular beds of the lungs and kidney. ET-1 forms an insoluble bond with the $\mathrm{ET}_{\mathrm{B}}$ that is internalized and degraded (D'Orleans-Juste et al 2002). Clearance of ET-1 is rapid. The biological half-life following intravenous injection of radio-iodinated peptide in the rat is about 1 minute, while the pressor effects are maintained for nearly an hour (Sirvio et al 1990; Vierhapper et al 1990). In a single pass through the lungs, the human pulmonary circulation extracts roughly 50\% of circulating ET-1 (Dupuis et al 1996). However, the arterio-venous ET-1 gradient is minimal due to a quantitatively similar degree of pulmonary ET-1 synthesis and release.

\section{Endothelin and pulmonary hypertension}

Circulating levels of ET-1 are elevated in PAH and ET-1 expression is increased in the plexiform lesions obstructing the pre-capillary pulmonary microvasculature (Matsui 2002). Furthermore, the magnitude of overexpression of ET-1 has been shown to correlate with disease severity, cardiopulmonary hemodynamics, and mortality (Cacoub et al 1993; Nootens et al 1995; Cacoub et al 1997; Galie et al 2004). ET-1 is a potent pulmonary vasoconstrictor and has antiapoptotic effects on endothelial cells and smooth muscle cells that may contribute to the pulmonary vascular abnormalities seen in PAH (Budhiraja et al 2004). Although the link between the pulmonary arterial vasculopathy seen in $\mathrm{PAH}$ and excess synthesis of ET- 1 is not fully understood at this time, the recognition that ET-1 contributes to the pathogenesis of PAH has led to the development of several ERAs that have demonstrated clinical efficacy (Motte et al 2006).

The ERAs work by blocking the 2 receptors that mediate the biologic functions of the endothelins. A strategically important question that arises is whether selective $\mathrm{ET}_{\mathrm{A}}$ receptor antagonism should result in better clinically efficacy than blockade of both $\mathrm{ET}_{\mathrm{A}}$ and $\mathrm{ET}_{\mathrm{B}}$ (Langleben 2007). In theory, selective $\mathrm{ET}_{\mathrm{A}}$ blockade would prevent the most salient vasoconstrictive and mitogenic effects of
ET-1 while maintaining $\mathrm{ET}_{\mathrm{B}}$ mediated release of $\mathrm{NO}$ and prostacyclin and maximal clearance of circulating ET-1 (Vatter and Seifert 2006). Indeed, Schroll et al found lower prostacyclin synthase expression in the pulmonary arteries of rats treated with bosentan than in those given ambrisentan (Schroll et al 2008). However, some studies suggest that dual blockade is necessary to achieve maximal vasodilation in pulmonary hypertension due to the vasoconstrictor effect of $\mathrm{ET}_{\mathrm{B}}$ on pulmonary vascular smooth muscle (Cacoub et al 1993; MacLean et al 1995; McCulloch and MacLean 1995; Nootens et al 1995; Cacoub et al 1997; McCulloch et al 1998; Galie et al 2004). Other studies suggest that selective $\mathrm{ET}_{\mathrm{A}}$ receptor antagonism may be more beneficial (Dupuis 2000). The potential advantage of a selective agent may reside in the relative importance of vasoconstriction mediated by $\mathrm{ET}_{\mathrm{B}}$. The in vitro effects of $\mathrm{ET}_{\mathrm{B}}$ activation varies with the cell type, the receptor-specific agonist used, and its concentration (Boss et al 2002). Previous studies support a much greater role for $\mathrm{ET}_{\mathrm{A}}$ than for $\mathrm{ET}_{\mathrm{B}}$ in the constrictive and proliferative responses of mesenchymal derived cells to ET-1 at concentrations similar to endogenous ET-1 levels seen in disease states (Shi-Wen et al 2004). However, animal studies have failed to demonstrate a significant advantage to selective endothelial receptor antagonism. For example, in monocrotaline-induced $\mathrm{PH}$, both the selective $\mathrm{ET}_{\mathrm{A}}$ blocker (darusentan $50 \mathrm{mg} / \mathrm{kg} /$ day) and the dual $\mathrm{ET}_{\mathrm{A}}$ and $\mathrm{ET}_{\mathrm{B}}$ antagonist (BSF-420627, $50 \mathrm{mg} / \mathrm{kg} /$ day) were effective in decreasing the severity of PH. Interestingly, decreased right ventricular hypertrophy and enhanced survival were seen only with the dual $\mathrm{ET}_{\mathrm{A}}$ and $\mathrm{ET}_{\mathrm{B}}$ antagonist, suggesting that non-selective $\left(\mathrm{ET}_{\mathrm{A}} / \mathrm{ET}_{\mathrm{B}}\right)$ might be superior to selective $\mathrm{ET}_{\mathrm{A}}$ antagonism (Jasmin et al 2001). On the other hand selective $\mathrm{ER}_{\mathrm{A}}$ blockade has been shown to blunt monocrotaline-induced increases in right ventricular ANP and beta myosin heavy chain mRNA, molecular markers for maladaptive cardiac hypertrophy (Miyauchi et al 2000). Whether or not the effects of ERAs on right ventricular hypertrophic responses in monocrotaline-induced $\mathrm{PH}$ are reproducible in patients with PAH remains to be established.

Two studies have demonstrated increased pulmonary vascular smooth muscle expression of $\mathrm{ET}_{\mathrm{B}}$ in human $\mathrm{PAH}$ (Bauer et al 2002; Davie et al 2002). ET $_{B}$ receptors are abundantly present in pulmonary vascular endothelial cells as well, particularly in the distal lung microvasculature (Davie et al 2002). However, the physiologic significance of these findings in PAH remains unclear. Increased expression of $\mathrm{ET}_{\mathrm{B}}$ in pulmonary vascular endothelial cells should enhance ET-1-mediated release of $\mathrm{NO}$ and prostacyclin 
while improving clearance of ET-1 from the circulation (de Nucci et al 1988), whereas increased expression of $\mathrm{ET}_{\mathrm{B}}$ in pulmonary vascular smooth muscle cells would be expected to increase vasoconstriction and perhaps worsen medial thickening. Langleben et al found that most PAH patients have intact endothelial $\mathrm{ET}_{\mathrm{B}}$-mediated clearance, despite a reduced microvascular surface area from vascular remodeling, suggesting that increased expression of $\mathrm{ET}_{\mathrm{B}}$ is needed to maintain normal endothelin clearance (Langleben et al 2006).

The ET receptor selectivity of presently available ERAs has been the topic of considerable debate. An $\mathrm{ET}_{\mathrm{A}}: \mathrm{ET}_{\mathrm{B}}$ binding ratio $>2000: 1$ in a standard in vitro assay is considered selective for $\mathrm{ET}_{\mathrm{A}}$ ( Sitbon et al 2004; Galie et al 2006). However, endothelin receptor binding specificity varies widely depending on the experimental system used (Black et al 2003). The degree of selectivity also relates to the concentration of the antagonist, so even a selective antagonist will become relatively less selective at very high doses. Given the wide variation in values obtained using different experimental systems, the definition of receptor selectivity is somewhat arbitrary. However, for the sake of clinical practice, most investigators consider bosentan to be a non-selective ERA (Clozel 2003) having only slightly greater affinity for $\mathrm{ET}_{\mathrm{A}}$ than $\mathrm{ET}_{\mathrm{B}}$ (approximately 4-100:1) (Morimoto et al 2001), whereas sitaxsentan and ambrisentan are considered selective $\mathrm{ET}_{\mathrm{A}}$ antagonists demonstrating far greater affinity for $\mathrm{ET}_{\mathrm{A}}$ than for $\mathrm{ET}_{\mathrm{B}}$ by 2 to 3 orders of magnitude.

\section{Development of ambrisentan}

Several different structural classes of ERAs, ranging from peptidic- and peptidomimetic structures to small organic molecules suitable for oral administration have been discovered within the last decade. Bosentan, one of the first orally active compounds with an antagonistic effect of $\mathrm{ET}_{\mathrm{A}}$ and $\mathrm{ET}_{\mathrm{B}}$, is a tetra-substituted pyrimidine (Clozel et al 1994). It was the first ERA approved for treatment of PAH in Europe and the US and its therapeutic efficacy has been demonstrated in several randomized, double-blind, placebo-controlled studies (Rich and McLaughlin 2003; Liu and Chen 2006).

The initial 3,3-diphenyl propionic acid based ERAs from BASF/Knoll were discovered by screening of BASF's chemical library for compounds that bind to recombinant human $\mathrm{ET}_{\mathrm{A}}$ receptor. Screening of those compounds, initially designed as herbicides, led to the discovery of a novel series of potent $\mathrm{ET}_{\mathrm{A}}$-selective antagonists. The attempts to simplify the structure and enhance the binding activity of these antagonists gave rise to LU-135252 (darusentan) the active enantiomer of racemic LU-127043. Darusentan is selective for $\mathrm{ET}_{\mathrm{A}}$; its $K \mathrm{~K}$-values for the displacement of ${ }^{[125 I]} \mathrm{ET}-1$ in human receptors expressed in the Chinese hamster ovary $(\mathrm{CHO})$ cells are $1.5 \mathrm{nM}_{\text {for }} \mathrm{ET}_{\mathrm{A}}$ - and $184 \mathrm{nM}$ for $\mathrm{ET}_{\mathrm{B}}$ (Riechers et al 1996; Prie et al 1997). Slight modification of the structure of darusentan led to a similar compound, LU 208075, which was subsequently named ambrisentan (Billman 2002; Bolli et al 2004).

As discussed earlier, selectivity of an ERA is usually determined by its ability to bind $\mathrm{ET}_{\mathrm{A}}$ and $\mathrm{ET}_{\mathrm{B}}$ in a standard in vitro assay. As with other ERA, the selectivity of abmbrisentan for $\mathrm{ET}_{\mathrm{A}}$ has varied considerably depending on the dose and model used. For example, the affinity of ambrisentan was approximately $1 \mathrm{nM}$ for $\mathrm{ET}_{\mathrm{A}}$ and $195 \mathrm{nM}$ for $\mathrm{ET}_{\mathrm{B}}$ in human ET-receptors expressed in CHO cells (Riechers et al 1996), but only 54-fold higher in intact CHO cell lines expressing recombinant human ET-receptors (Bolli et al 2004), 77-fold higher in canine cells (Ki-values: $0.63 \mathrm{nM}$ ETA; $48.7 \mathrm{nM} \mathrm{ET}_{\mathrm{B}}$ ) (Amberg et al 1999) and 29-fold higher in rat tracheal and aortic smooth muscle (Bolli et al 2004). These values are similar to those obtained by Vatter et al who found that the selectivity of ambrisentan for $\mathrm{ET}_{\mathrm{A}}$ in ET-1-induced contraction of cerebral arteries of rats was approximately one logarithmic unit greater than $\mathrm{ET}_{\mathrm{B}}$ (Vatter et al 2003). In contrast, studies using human ventricular myocyte-derived $\mathrm{ET}_{\mathrm{A}}$ and $\mathrm{ET}_{\mathrm{B}}$ receptors have shown that the $\mathrm{K}_{\mathrm{i}}$ (dissociation constant for the inhibitor) of ambrisentan for $\mathrm{ET}_{\mathrm{A}}$ is, approximately $0.011 \mathrm{nM}$, more than 400-fold higher than for $\mathrm{ET}_{\mathrm{B}}$ (Greene 2006). At therapeutically relevant plasma concentrations in $\mathrm{PAH}$, ambrisentan has higher receptor occupancy with $\mathrm{ET}_{\mathrm{A}}(>90 \%)$, than $\mathrm{ET}_{\mathrm{B}}(<10 \%)$. Despite this, the reported selectivity of ambrisentan for ET A $_{\text {only }}$ 77/1 (Amberg et al 1999), is somewhat less than the generally accepted ratio needed for the qualification as a selective $\mathrm{ET}_{\mathrm{A}}$ receptor antagonist. Furthermore, significant increases in plasma ET-1 levels have been reported 2 hours after ingestion of ambrisentan suggesting at least some functional antagonism of $\mathrm{ET}_{\mathrm{B}}$ in vivo (FDA 2007; Opitz et al 2008).

\section{Pharmacokinetics of ambrisentan}

Ambrisentan, differs from bosentan and sitaxsentan in that it is a propanoic acid-class molecule rather than a sulfonamideclass agent. The chemical composition of ambrisentan, also known as LU 208075 or BSF 208075, is $\mathrm{C}_{22} \mathrm{H}_{22} \mathrm{~N}_{2} \mathrm{O}_{4}$, and its molecular weight is $378.4 \mathrm{~g} / \mathrm{mol}$ (Rubin et al) (Figure 1). Ambrisentan is rapidly absorbed into the systemic circulation after oral administration, with high bioavailability of about $90 \%$ of the ingested dose and a duration of action 


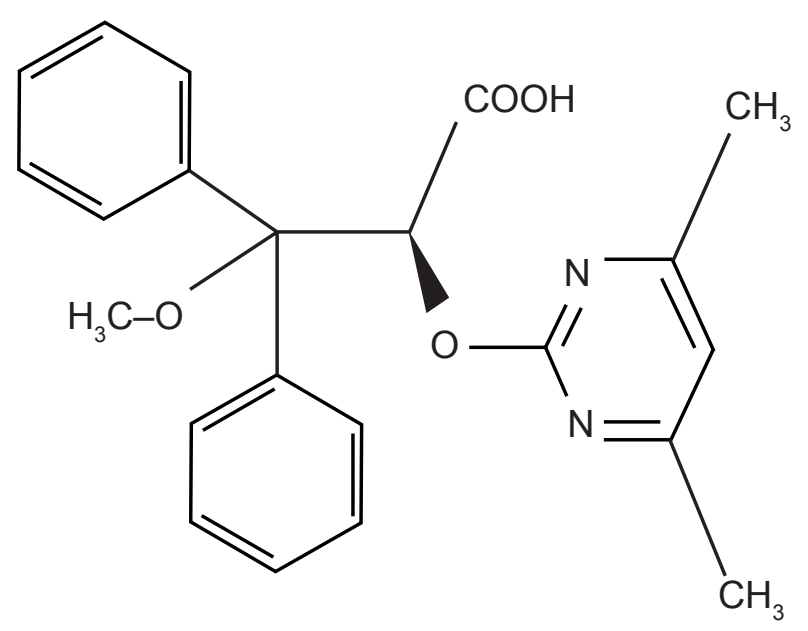

Figure I Molecular structure of ambrisentan.

longer than 6 hours (Amberg et al 1999; Hopfner 1999). In a Phase II trial of patients suffering from PAH, plasma levels of ambrisentan reached $\mathrm{C}_{\max }$ between 1.7 and 3.3 hours after oral administration (Galie et al 2005a). The pharmacokinetics of ambrisentan are dose-linear over a range of 1 to $100 \mathrm{mg}$ and are not affected by food intake. Steady-state is achieved after 3 to 4 days of once-daily oral dosing, and the pharmacokinetics of multiple doses (ie, steady-state ambrisentan) are consistent with observations after a single dose. The steady-state elimination half-life of ambrisentan in PAH patients is approximately 15 hours for the $5 \mathrm{mg}$ dose and ranges from 13.6 to 16.5 hours in normal subjects, providing the rationale for once-daily dosing.

Ambrisentan undergoes little metabolism and is excreted mostly unchanged in bile. Following oral administration of a radio-labeled dose in preclinical studies, ambrisentan was detected primarily in the liver and plasma 2 to 4 hours after administration. The majority of the radio-labeled dose was recovered in the feces as unchanged or glucuronideconjugated drug (FDA 2007; Cheng 2008).

\section{Clinical efficacy}

Clinical trials with ambrisentan have been performed since 2001, but the initial Phase II trials conducted in patients with hypertension, renal failure, cardiac failure, or cardiovascular diseases were not reported in the literature. Clinical data from the Phase II dose ranging trial in patients with PAH were published in 2005 (Galie et al 2005a). In addition, the results of 2 parallel, Phase III, randomized controlled trials with ambrisentan have recently been published in one paper (Galie et al 2008) and a open-label study of patients treated with ambrisentan after developing elevated liver function tests (LFTs) while taking bosentan has been published in abstract form (McGoon et al 2006).

In the Phase 2, double-blind, non-controlled dose-ranging study, 64 patients with idiopathic PAH or PAH associated with connective tissue disease, anorexigen use, or HIV were randomized to receive oral ambrisentan $1,2.5,5$, or $10 \mathrm{mg}$ once-daily for 12 weeks, followed by a 12-week open-label treatment period (Galie et al 2005a). All patients were WHO functional class II or III at baseline. Six patients discontinued the study prior to the 12 -week period. The last data obtained from these 6 patients were carried forward to the 12 week time point. Fifty-six of the remaining 58 patients were enrolled in an additional 12-week open label study. The primary endpoint was the change from baseline in 6-minute walking distance (6MWD) after 12 weeks. Secondary endpoints included change from baseline in WHO functional class, Borg dyspnea index (BDI), subject global assessment, and cardiopulmonary hemodynamics. When data from all 4 dose groups were combined the mean increase in 6MWD after 12 weeks of therapy was $36.1 \mathrm{~m}$ ( $\mathrm{p}<0.0001$ ). A similar improvement from baseline 6MWD was observed for each dose of ambrisentan tested: $+33.9(p=0.0029),+37.1$ $(p=0.0004),+38.1(p=0.0112)$, and $+35.1(p=0.0080) m$ for the 1-, 2.5-, 5-, and 10-mg-dose groups, respectively, suggesting no dose-response relationship. Subgroup analyses indicate that the 6MWD increased in patients with IPAH $(+39.9 \mathrm{~m}, \mathrm{p}<0.0001)$ as well as in patients with PAH due to other etiologies $(+30.2 \mathrm{~m}$, for PAH associated with connective tissue disease, anorexigen use, and HIV combined $\mathrm{p}=0.0026$ ). The magnitude of increase in 6MWD was comparable in WHO functional class II and III. Exercise capacity continued to increase throughout the 12-week open-label period, reaching a maximum improvement from baseline of $54 \mathrm{~m}$ at week 24 .

Improvements in WHO functional class were observed for all dose groups. Eighteen (36\%) patients improved by 1 or more WHO functional classes, whereas only $2(3.4 \%)$ patients deteriorated in WHO functional class. By week 12, clinical worsening of PAH was observed in 13 of 64 patients (20.3\%). In 6 (46.2\%) of the 13 patients clinical worsening of PAH was defined as an increase in the dose of diuretic. During the open-label extension period, there were 8 patients in whom clinical worsening developed and 5 were attributable to an increased dose of diuretic. At week 12 , there was a mean improvement from baseline indicated by a decrease in the Borg dyspnea index score of $0.6 \pm 0.5$, 
$0.9 \pm 0.4,1.0 \pm 0.6$, and $1.0 \pm 0.6$ for the 1-, 2.5-, 5-, and 10-mg-dose groups, respectively. The Borg dyspnea index score at baseline for all dose groups combined was $4.0 \pm 0.3$, which improved $-0.9 \pm 0.3(\mathrm{p}=0.0015)$ at week 12 and was maintained through week $24(-1.3 \pm 0.3, p<0.0001)$. Significant improvements were also observed in quality of life, as measured by a subject global assessment (11.3 \pm 2.4 and $12.1 \pm 2.7 \mathrm{~mm}$ at weeks 12 and 24 , respectively; $\mathrm{p}<0.0001$ ). A subgroup of 29 patients (8-9 patients for the $1,2.5$, and $5 \mathrm{mg}$ doses and 3 patients in the $10 \mathrm{mg}$ group) underwent hemodynamic testing at baseline and after completing 12 weeks of therapy. In the combined analysis of all dose groups, cardiac index increased $\left(0.33 \pm 0.47 \mathrm{~L} / \mathrm{min} / \mathrm{m}^{2}\right)$, and mean pulmonary arterial pressure and pulmonary vascular resistance decreased compared with baseline $\left(-5.2 \pm 6.2 \mathrm{~mm} \mathrm{Hg}\right.$ and $-226 \pm 202$ dyne.cm $/ \mathrm{sec}^{2}$, respectively, $\mathrm{p}<0.05$ for both). Overall, ambrisentan was well tolerated. Only 2 out of 64 patients developed elevation in LFTs $>3$ times the upper limit of normal during the first 24 weeks of therapy. Patients who completed the 24-week study were eligible to participate in a long-term, open-label extension study. Fifty-four patients continued treatment and 50 of these patients were receiving ambrisentan monotherapy after 48 weeks of treatment. A combined analysis of the overall patient population demonstrated that the clinical benefits of ambrisentan were sustained over the 1-year study period, including improvements in 6MWD (mean increase $55 \pm 55 \mathrm{~m}, \mathrm{p}<0.0001$ for all dose groups combined), BDI, and WHO functional class (Galie et al 2005b).

After the initial dose ranging study, 2 Phase III trials with ambrisentan were initiated (Galie et al 2008). Both trials were named ARIES (AmbRISentan in patients with moderate to severe $\mathrm{PAH}$ ) and were randomized, placebo controlled, double blinded investigations with an identical design except for the dose of ambrisentan. In ARIES-1, patients from the US and Australia with idiopathic PAH or PAH associated with connective tissue disease, HIV infection or anorectic drug use were randomized to $5 \mathrm{mg}$ or $10 \mathrm{mg}$ ambrisentan daily or placebo. The same entry criteria were used for the ARIES-2 study in Europe, Africa and South America, but patients were randomized to 2.5 or $5 \mathrm{mg}$ of ambrisentan or placebo.

All randomized patients received at least 1 dose of study drug, except for 1 patient in the 10-mg group of ARIES-1 who was not included in the analysis of safety or efficacy. An increase in 6MWD was observed in each ambrisentan dose group at week 4 , and this effect was maintained at weeks 8 and 12 , whereas in the placebo group, it deteriorated by week 12 (Figure 2). The mean placebo-corrected treatment effects at week 12 were $31 \mathrm{~m}$ (95\% confidence interval [CI], 3 to $59 ; \mathrm{p}=0.008)$ for ambrisentan $5 \mathrm{mg}$ and $51 \mathrm{~m} \mathrm{(95 \%} \mathrm{CI,}$ 27 to $76 ; \mathrm{p}<0.001$ ) for ambrisentan $10 \mathrm{mg}$ in ARIES-1; $32 \mathrm{~m}$ (95\% CI, 2 to $63 ; \mathrm{p}=0.022$ ) for ambrisentan $2.5 \mathrm{mg}$ and $59 \mathrm{~m}(95 \% \mathrm{CI}, 30$ to $89 ; \mathrm{p}<0.001)$ for ambrisentan $5 \mathrm{mg}$ in ARIES-2; and $45 \mathrm{~m}(95 \% \mathrm{CI}, 24$ to 65 ; p < 0.001) for the combined 5-mg group from both studies. In both studies, improvements in the mean placebo-corrected 6MWD were observed at week 12 in patients with baseline WHO functional class II (range, 36 to $55 \mathrm{~m}$ ) and WHO functional class III (range, 39 to $45 \mathrm{~m}$ ). Similarly, improvements in placebo corrected 6 MWD were observed in both idiopathic PAH patients (range, 50 to $66 \mathrm{~m}$ ) and, to a lesser extent, for patients with $\mathrm{PAH}$ associated with connective tissue disease (range, 15 to $23 \mathrm{~m}$ ).

In ARIES-2, patients treated with ambrisentan had a longer time before clinical worsening, a composite endpoint defined as death, hospitalization for PAH, lung transplantation, atrial septostomy, withdrawal from the study to initiate therapy with other PAH medications, or early escape criteria (Figure 3) $(\mathrm{p}<0.001$ for both ambrisentan doses combined versus placebo). Similar results were observed for the 2.5- and 5-mg ambrisentan groups separately $(\mathrm{p}=0.005, \mathrm{P}=0.008)$. Time to clinical worsening was not significantly different in ambrisentan and placebo treated patients in ARIES-1 ( $p=0.307, p=0.292$, and $p=0.214$, for the 5-mg group, 10-mg group, and combined groups, respectively). However, the rate of clinical worsening for the placebo groups was considerably lower in ARIES-1 than in ARIES-2 (9\% versus 22\%) and the lack of difference in rates of worsening between placebo and ambrisentan treated patients in ARIES-1 was due more to the lower rate of deterioration in the placebo group than to a higher rate of worsening in the ambrisentan treated group. In fact, the rates of clinical worsening for patients treated with ambrisentan were nearly identical in ARIES- 1 and -2 (4\% versus 5\%, respectively) and a statistically significant improvement in time to clinical worsening was observed for the combined 5-mg groups compared with the combined placebo groups from both studies $(\mathrm{p}=0.005)$.

In ARIES-1 and -2, WHO functional class decreased more in the placebo treated group than in the ambrisentan groups, however, the difference was statistically significant only in ARIES-1 ( $p=0.036$ and $p=0.117$, for ARIES- 1 and ARIES-2, respectively) For ARIES-1 and -2, WHO class in the combined 5-mg group improved from baseline to week 12 compared with the combined placebo group 


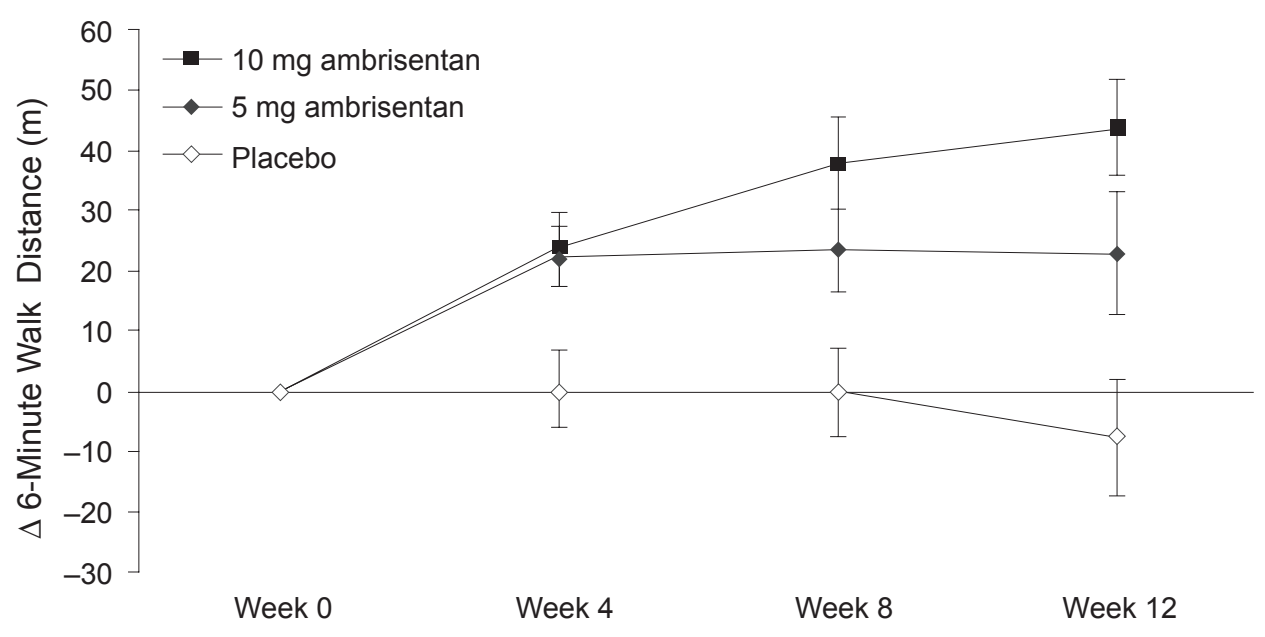

ARIES-1

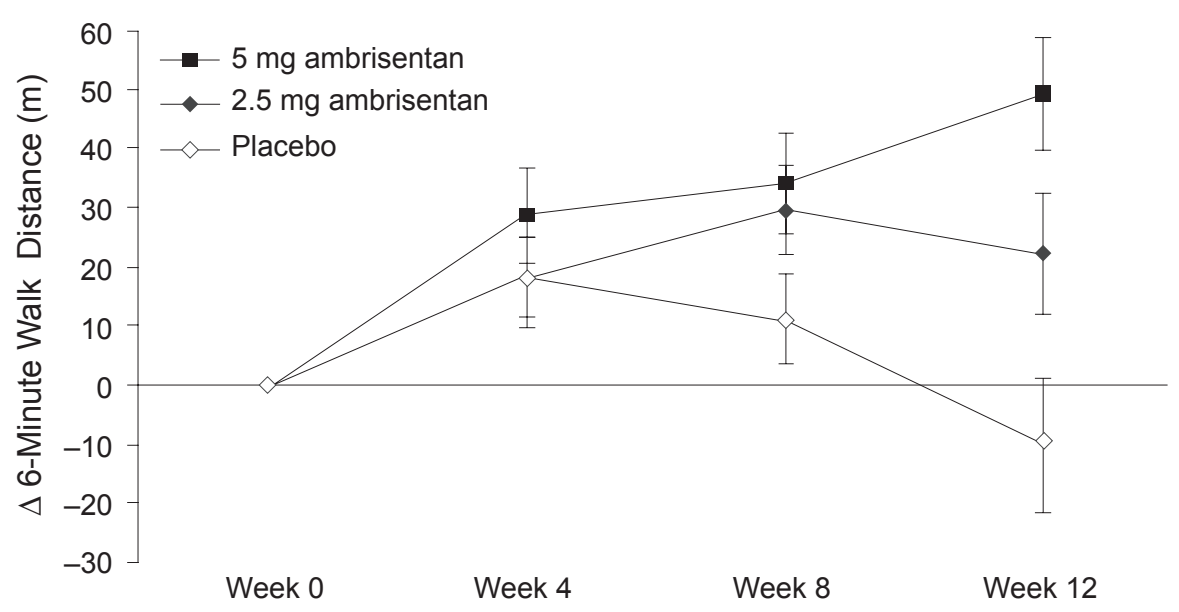

ARIES-2

Figure 2 Changes from baseline in the 6-minute walking distance at week I 2 in the placebo and ambrisentan groups from the ARIES-I and ARIES-2 studies. For ARIES-I, $\mathrm{p}=0.008$ and $\mathrm{p}<0.00 \mathrm{I}$ for the 5-mg and 10-mg ambrisentan groups vs placebo, respectively. In ARIES-2, $\mathrm{p}=0.022$ and $\mathrm{p}<0.00 \mathrm{I}$ for the 2.5 -mg and 5 -mg ambrisentan groups vs placebo, respectively.Values shown are mean \pm SE. Reproduced with permission from Galie N, Olschewski H, Oudiz RJ, et al 2008. Ambrisentan for the treatment of pulmonary arterial hypertension: results of the ambrisentan in pulmonary arterial hypertension, randomized, double-blind, placebo-controlled, multicenter, efficacy (ARIES) study I and 2. Circulation, I I7:3010-9. Copyright (C) 2008. Lippincott Williams \& Wilkins.

$(\mathrm{p}=0.025)$. In both studies, the treatment effects observed were due primarily to less WHO functional class deterioration in patients receiving ambrisentan compared with patients receiving placebo (ARIES-1, 3.0\% and 16.4\%, respectively; ARIES-2, 3.9\% and $18.5 \%$, respectively).

In ARIES-2, the SF-36 Health Survey Physical Functioning scale significantly improved $(\mathrm{P}=0.005)$ in the combined ambrisentan group $(3.41 \pm 6.96)$ compared with the placebo group $(-0.20 \pm 7.14)$; improvements in this parameter also were noted in the individual $2.5-\mathrm{mg}(\mathrm{p}=0.005)$ and 5 -mg $(p=0.040)$ dose groups. Furthermore, improvements were observed in several other SF-36 scales, including Role-Physical, Vitality, Role-Emotional, and General Health.
In ARIES-1, similar trends were observed without statistical significance (Rubin 2002).

An improvement in BDI was observed at week 12 for the combined ambrisentan group compared with placebo in ARIES-1 $(-0.6 ; 95 \% \mathrm{CI},-1.2$ to $0.0 ; \mathrm{p}=0.017)$ and ARIES-2 $(-1.1 ; 95 \% \mathrm{CI},-1.8$ to $-0.4 ; \mathrm{p}=0.019)$. Improvements in Borg dyspnea score compared with placebo also were noted for the 10-mg group in ARIES-1 $(-0.9 ; 95 \%$ $\mathrm{CI},-1.6$ to $-0.2 ; \mathrm{p}=0.002)$, for the $2.5-\mathrm{mg}(-1.0 ; 95 \% \mathrm{CI}$, -1.9 to $-0.2 ; \mathrm{p}=0.046)$ and $5-\mathrm{mg}(-1.2 ; 95 \% \mathrm{CI},-2.0$ to $-0.4 ; \mathrm{p}=0.040)$ groups in ARIES-2, and for the combined 5 -mg group $(-0.7 ; 95 \% \mathrm{CI},-1.3$ to $-0.2 ; \mathrm{p}=0.031)$ from both studies. 


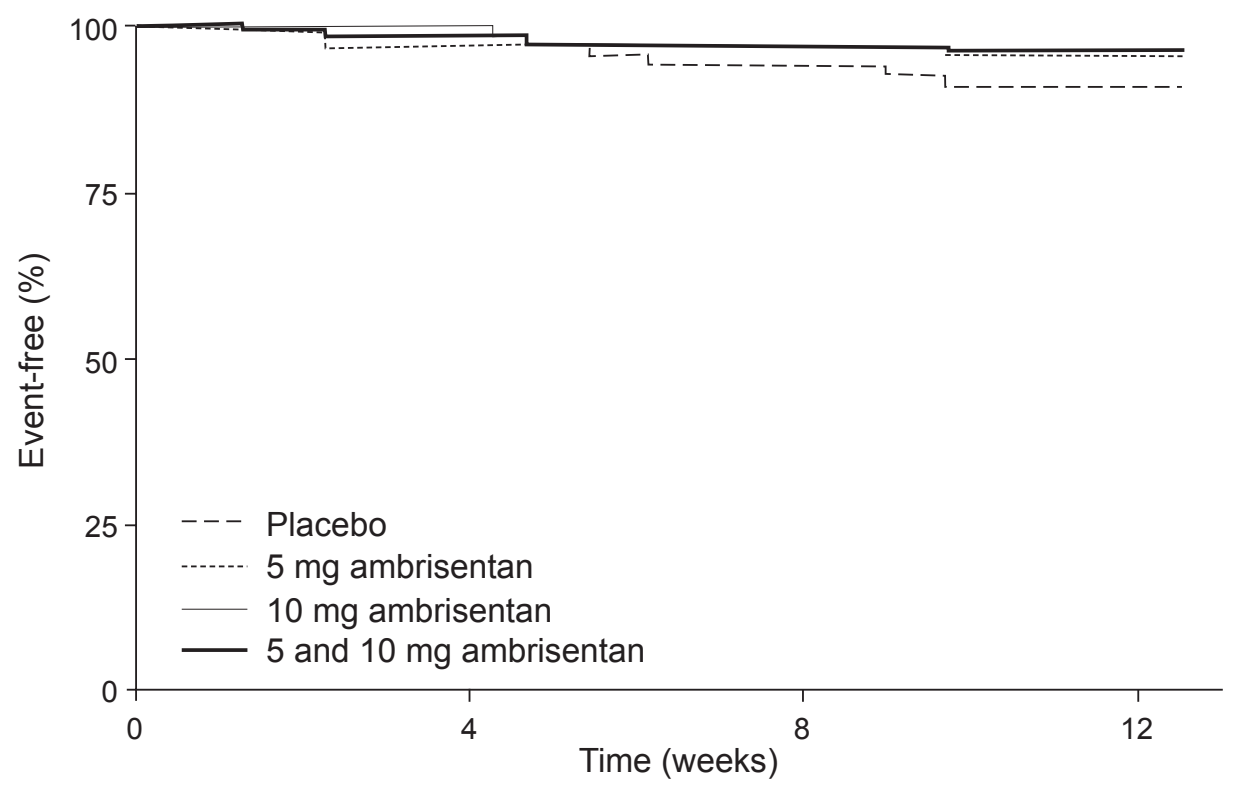

ARIES-1

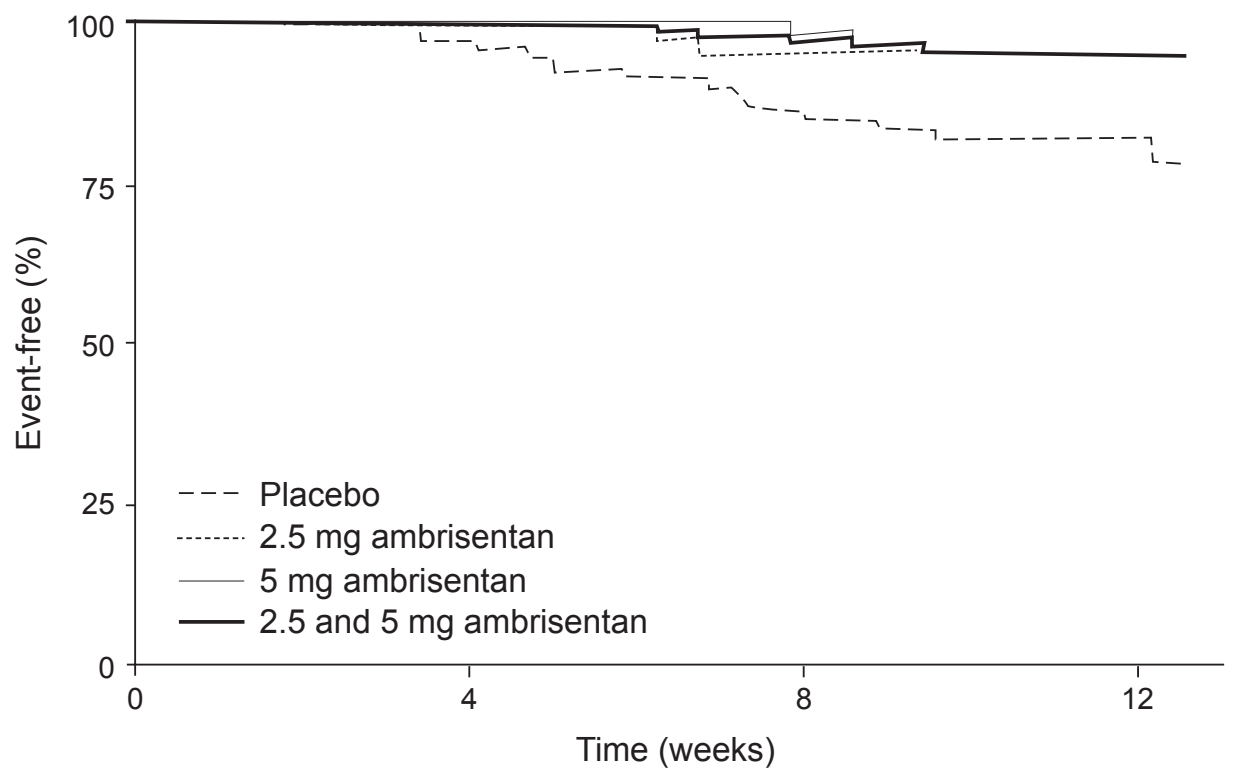

ARIES-2

Figure 3 Kaplan-Meier estimates of the proportion of patients with clinical worsening in the ARIES-I and ARIES-2 studies. See text for definition of clinical worsening. In ARIES-I, no significant differences were seen between the ambrisentan 5 -mg and I0-mg groups vs placebo or the 5 -mg and I0-mg groups combined vs placebo. In ARIES-2, $\mathrm{p}=0.005$, $\mathrm{p}=0.008$, and $\mathrm{p}<0.00 \mathrm{I}$ for the ambrisentan $2.5-\mathrm{mg}, 5-\mathrm{mg}$, and 2.5 plus 5-mg dose groups combined, respectively. Reproduced with permission from Galie N, Olschewski H, Oudiz RJ, et al 2008. Ambrisentan for the treatment of pulmonary arterial hypertension: results of the ambrisentan in pulmonary arterial hypertension, randomized, doubleblind, placebo-controlled, multicenter, efficacy (ARIES) study I and 2. Circulation, I 17:3010-9. Copyright @ 2008. Lippincott Williams \& Wilkins.

No assessment of cardiopulmonary hemodynamics was made in either ARIES study. However, baseline and 12 week treatment levels of B-type natriuretic peptide (BNP) were measured. Plasma BNP levels have been shown to correlate inversely with survival in PAH. In particular, a baseline BNP level of $>155 \mathrm{pg} / \mathrm{mL}$ has been associated with increased mortality as has a failure to decrease $\mathrm{BNP}<180 \mathrm{pg} / \mathrm{mL}$ after therapy (Nagaya et al 2000). In both ARIES studies, plasma BNP levels were similar at baseline in the placebo and ambrisentan groups. At week 12, plasma BNP concentrations in the placebo groups increased slightly from baseline by 9\% and $13 \%$ (ARIES-1 and ARIES-2, respectively). In contrast, plasma BNP levels decreased from baseline in the $5-\mathrm{mg}(30 \%)$ and $10-\mathrm{mg}$ (45\%) groups in ARIES-1 and in the 
2.5-mg (29\%) and 5-mg (30\%) groups in ARIES-2 ( $p<0.003$ for each dose group). Mean BNP levels after 12 weeks of treatment were $>$ than $100 \mathrm{pg} / \mathrm{mL}$ in placebo groups from both studies and $<100 \mathrm{pg} / \mathrm{mL}$ in each of the 4 ambrisentan dose groups.

Of the 361 patients who entered into the long-term extension study, 43 discontinued before completing 48 weeks of treatment. Fourteen of the 43 died. The 43 patients who discontinued had more severe disease at baseline, as evidenced by a lower baseline 6MWD, a higher baseline BDI, and a worse baseline WHO functional class. A total of 298 out of the 318 patients who remained in the extension study received at least 48 weeks of ambrisentan therapy. Twenty additional patients remained in the study but had received less than 48 weeks of therapy at the time data were analyzed (November 30, 2006). Eighteen of the 298 patients received additional treatments (prostanoids or phosphodiesterase type 5 inhibitors) during the extension study. For the 280 patients receiving ambrisentan monotherapy for 48 weeks the mean change from baseline in 6MWD was $40 \mathrm{~m}(95 \% \mathrm{CI}, 33$ to $48 \mathrm{~m})$ at week 12 and $39 \mathrm{~m}$
(95\% CI, 29 to $49 \mathrm{~m}$ ) at week 48, suggesting that the initial improvement in exercise capacity was sustained for nearly a year.

\section{Safety}

Ambrisentan was generally well tolerated in the few clinical studies that have been completed thus far. The most frequently reported adverse events during the Phase 2 , dose-ranging study were peripheral edema, nasal congestion, upper respiratory tract infection, headache, flushing, and nausea (Galie et al 2005a). None of these symptoms appeared to occur more frequently at higher doses of ambrisentan, although the number treated with each dose was small. Ambrisentan was well tolerated throughout the 1 -year extension study, with only 1 patient requiring discontinuation due to elevated hepatic aminotransferases. In the ARIES-1 and -2 studies, the most common adverse effects in patients who received ambrisentan were, again peripheral edema, sinusitis, naropharyngitis, nasal congestion and flushing (Table 2). Interestingly, peripheral edema, the

Table 2 Incidence of serum aminotransferase elevation in clinical trials of endothelin receptor antagonists for the treatment of pulmonary hypertension

\begin{tabular}{|c|c|c|c|c|c|c|}
\hline Study & Reference & Drug & Dose & $\mathbf{n}$ & $\begin{array}{l}\text { Study } \\
\text { Length }\end{array}$ & $\begin{array}{l}\text { LFT elevation* } \\
\text { (\%) }\end{array}$ \\
\hline \multirow[t]{3}{*}{ BREATHE-I } & Rubin et al 2002 & Placebo & & 69 & 16 weeks & \\
\hline & & Bosentan & $125 \mathrm{mg}$ bid & 74 & & 4 \\
\hline & & & $250 \mathrm{mg}$ bid & 70 & & 14 \\
\hline \multirow[t]{6}{*}{ STRIDE-I } & Barst et al 2004 & Placebo & & 60 & 12 weeks & 3 \\
\hline & & Sitaxsentan & 100 mg qd & 55 & & 0 \\
\hline & & & $300 \mathrm{mg}$ qd & 63 & & 10 \\
\hline & & & & & 26 weeks & \\
\hline & & Sitaxsentan & 100 mg qd & & & 5 \\
\hline & & & $300 \mathrm{mg}$ qd & & & 21 \\
\hline \multirow[t]{4}{*}{ STRIDE-2 } & Barst et al 2006 & Placebo & & 51 & 18 weeks & 6 \\
\hline & & Sitaxsentan & $50 \mathrm{mg}$ qd & 54 & & 3 \\
\hline & & & 100 mg qd & 57 & & 5 \\
\hline & & Bosentan & $125 \mathrm{mg}$ bid & 52 & & 11 \\
\hline Ambrisentan Dose & Galie et al 2005 & & I mg qd & 16 & 24 weeks & 0 \\
\hline \multicolumn{7}{|l|}{ Ranging Study } \\
\hline & & & $2.5 \mathrm{mg}$ qd & 19 & & 10.5 \\
\hline & & & $5 \mathrm{mg} q \mathrm{~d}$ & 16 & & 12.5 \\
\hline & & & $10 \mathrm{mg}$ qd & 13 & & 0 \\
\hline \multirow[t]{4}{*}{ ARIES I + 2} & Galie et al 2008 & & Placebo & 132 & 12 weeks & 2.3 \\
\hline & & & 2.5 & 64 & & 0 \\
\hline & & & 5 & 130 & & 0 \\
\hline & & & 10 & 68 & & 0 \\
\hline
\end{tabular}

LFT - liver function tests, *Elevation of serum hepatic aminotransferase levels greater than 3 times the upper limit of normal. 
most common adverse effect reported, occurred more than twice as often in patients given ambrisentan than in those who received placebo in AIRES-1, (27.6 versus 10.4\%) but was the same for ambrisentan and placebo treated patients in AIRES-2 (6.2 versus $10.8 \%$ for ambrisentan versus placebo, respectively). During the 12-week study period in ARIES-1 and -2 , there were no significant changes from baseline in prothrombin time or international normalized ratio in the ambrisentan- or placebo-treated groups.

Although no study has compared the incidence of liver function abnormalities necessitating discontinuation of therapy between ambrisentan and other ERAs, the overall incidence of serum aminotransferase elevation has been somewhat lower with ambrisentan than in similar studies with bosentan and sitaxsentan (Table 2). During the Phase 2, 24-week study, $2(3 \%)$ patients experienced elevations in hepatic aminotransferases $>3$ times the upper limit of normal (ULN), that necessitated dose reduction or drug discontinuation. Two patients had isolated aminotransferase elevations that were unconfirmed upon retest and required no change in treatment. At the start of the long-term extension study (ie, after 24 weeks of ambrisentan treatment), $48 \%$ of patients were receiving the maximal dose of ambrisentan $(10 \mathrm{mg})$ and no additional elevations of alanine aminotransferase (ALT) or aspartate aminotransferase $($ AST) $>3$ times ULN were observed after one year follow-up. In ARIES-1 and -2 , none of the 261 patients receiving ambrisentan developed serum ALT or AST $>3$ times ULN during the first 12 weeks of therapy compared with 3 patients $(2.3 \%)$ in the placebo groups. Moreover, mean values for, AST, ALT, total bilirubin, and alkaline phosphatase did not increase from baseline in the ambrisentan groups. These results compare favorably to the $4 \%$ to $14 \%$ incidence of serum aminotranferase elevation $>3$ times ULN in clinical trials of bosentan and the $3 \%$ to $6 \%$ incidence of elevated liver function tests reported with sitaxsentan (Table 2) (Rubin et al 2002; Barst et al 2004; Barst et al 2006; Provencher et al 2006; Benza et al 2008).

The incidence of aminotransferase elevation with ambrisentan does not appear to be dose related, whereas both bosentan and sitaxsentan demonstrate increased hepatotoxicity at higher doses (Table 2). For example, the incidence of serum aminotransferase elevation in one trial of bosentan was 3 times higher in patients assigned to $250 \mathrm{mg}$ bid (14\%) than in those receiving the currently approved dose of $125 \mathrm{mg}$ bid (4\%) for a mean duration of 129 days (Rubin et al 2002) Likewise, the incidence of LFT elevation was $21 \%$ and $5 \%$ for patients receiving $300 \mathrm{mg}$ and $100 \mathrm{mg}$ daily, respectively for up to 58 weeks (median 26 weeks) (Barst et al 2004).

Recently, results from an open-label Phase 2 study of ambrisentan in patients with PAH who had previously discontinued bosentan and/or sitaxsentan because of increased liver aminotransferase levels were reported (McGoon et al 2008). Thirty-six patients were evaluated. 31 had discontinued bosentan, 2 had discontinued sitaxsentan, and 3 had discontinued both. The median duration of treatment with an ERA prior to discontinuation was 9 weeks. None of the 36 patients enrolled in the study had a recurrence of liver function abnormalities that resulted in discontinuation of ambrisentan during the initial 12-week evaluation period. One patient experienced a transient increase in hepatic aminotransferases $>3$ times ULN that resulted in dose reduction. No further elevations $>3$ times ULN were observed with ambrisentan exposure after 1 year. Thus, the incidence of elevated liver function tests with ambrisentan appears to be lower than other ET receptor antagonistswith a pyrimidine structure such as bosentan or sitaxsentan. However, it should be noted that most of the LFT abnormalities associated with sitaxsentan have been seen with the 300-mg daily dose that is note approved for treatment. At the presently approved dose of $100 \mathrm{mg}$ daily, the incidence of LFT elevation $>3$ times the upper limit or normal appears to be similar in sitaxsentan and ambrisentan (Benza et al 2008; Galie et al 2005).

Interestingly, no clinically relevant increase in hepatic aminotransferases was reported in the clinical trials with darusentan, another diphenyl propionic acid derivatives (Luscher et al 2002; Anand et al 2004). It is possible that the lower rate of elevated liver function tests associated with ambrisentan may be due to its cytochrome p450 independent metabolism (Cernacek et al 1998). However, it should be recognized that significant elevations in serum aminotransferases have been reported with ambrisentan and that all patients receiving ambrisentan are required by the FDA to have liver function tests monitored monthly for as long as they are on therapy.

Decreases in hemoglobin concentration have also been recognized as a class effect associated with ERAs (Galie et al 2005a). In the Phase 2 ambrisentan trial, decreases in hemoglobin concentrations were observed as early as week 2 and remained stable throughout the 12-week study (mean change from baseline to week 12 was $-0.8 \mathrm{~g} / \mathrm{dL}$ ); however no further decreases were observed during the subsequent 12-week, open-label treatment period. In ARIES 1 and 2 the mean hemoglobin concentration fell by $0.84 \pm 1.2 \mathrm{~g} / \mathrm{dL}$ in patients receiving ambrisentan compared with a $0.2 \pm 1.0 \mathrm{~g} / \mathrm{dL}$ 


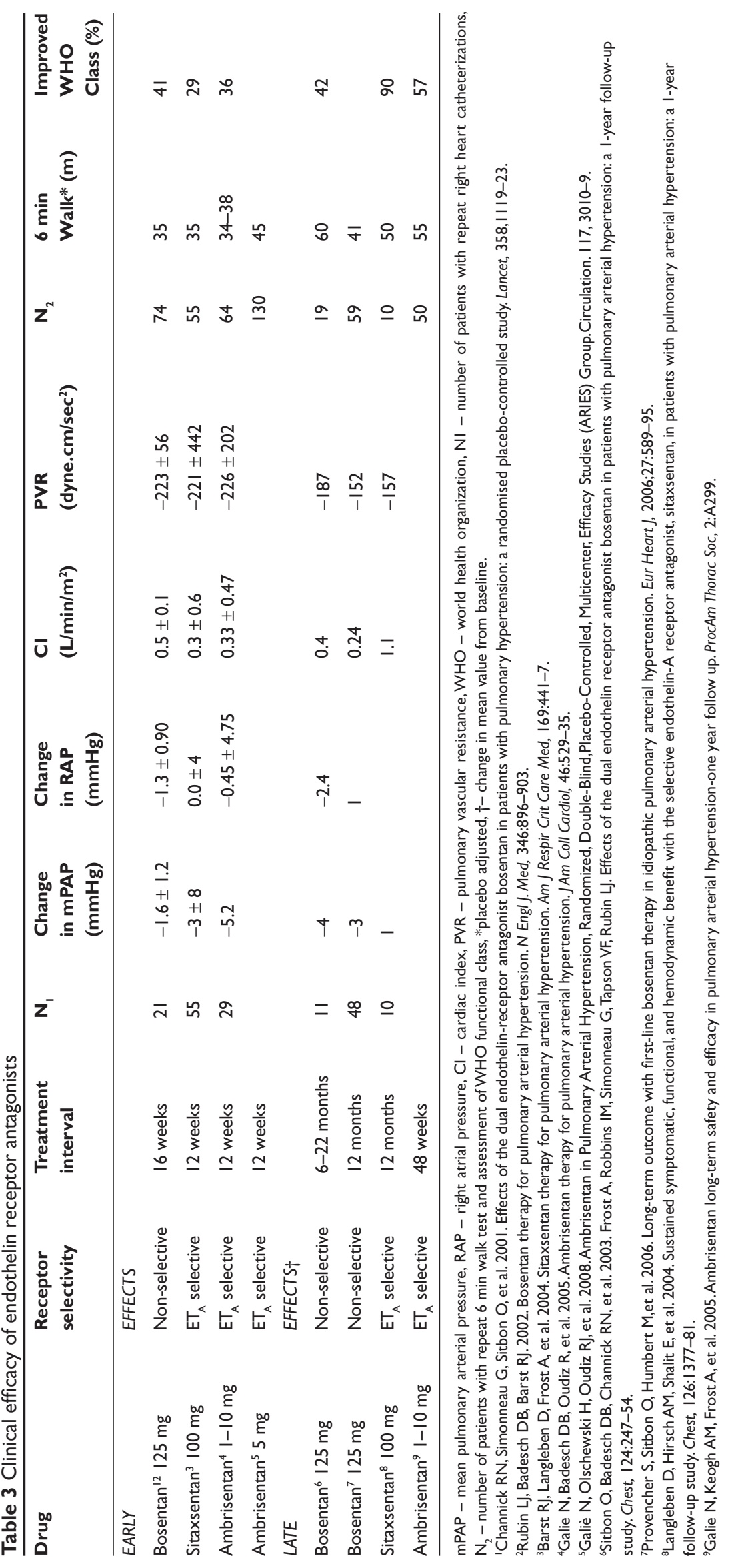


increase in the placebo group, but the change was not dose dependent.

\section{Ambrisentan therapy for PAH}

Data from the inital open label dosing study and the subsequent 2 concurrent, randomized, double blind, placebo-controlled studies demonstrate that ambrisentan improves 6MWD in patients with $\mathrm{PAH}$ and, at the $5 \mathrm{mg}$ /day dose, delays time to clinical worsening. At the same time, adverse events were similar to those experienced in clinical trials with other ERAs, with the exception of a lower incidence of serum aminotransferase elevation than in clinical trials of bosentan or sitaxsentan. Ambrisentan was well tolerated in a small number of patients who experienced amiontransferase elevation with other ERAs (McGoon et al 2008), although it is not known whether these patients would have experienced repeat elevation in aminotransferase levels had they been re-challenged with their original ERA. Despite their marked differences in endothelin receptor selectivity, clinical responses to all 3 agents have been strikingly similar (Bayes et al 2006; Torres 2007). Placebo adjusted improvements in cardiopulmonary hemodynamics, exercise capacity, and functional status have been essentially the same with bosentan, sitaxsentan and ambrisentan in short term placebo controlled trials and in longer term open label studies (Table 3). Survial data beyond a year is only available for bosentan. Thus, it is not yet known whether selective or non-selective ERAs have a greater effect on mortality. The question of whether differential blockade of $\mathrm{ET}_{\mathrm{A}}$ offers any advantages in the treatment of PAH would be best answered by randomized clinical trials comparing $\mathrm{ET}_{\mathrm{A}}$ selective and non-selective agents. Unforutnately, comparative trials of ambrisentan versus other ERAs have not been done. The large number of patients needed to detect small differences between presently available ERAs may make these studies untenable. Thus, it is not possible to determine if there are significant differences in safety or efficacy between these agents. Until more long-term data with ambrisentan are available, the benefits of once daily dosing and lower incidence of elevated liver function tests should be weighed against the greater clinical experience with the other ERAs in the treatment of PAH.

It is also important that ambrisentan, like other ERAs be utilized in the appropriate clinical setting. In a retrospective review of 103 consecutive PAH patients in WHO functional class III or IV, Provencher and colleagues found that $44 \%$ of patients who were started on monotherapy with bosentan required addition of prostanoid therapy within 2 years
(Provencher et al 2006). Clinical characteristics that predicted worse long-term response to bosentan therapy, included WHO functional class IV at baseline, failure to improve from WHO functional class III after 4 months of treatment, a 6MWD shorter than $250 \mathrm{~m}$ at baseline, a decrease of more than $10 \%$ in $6 \mathrm{MWD}$ on 2 consecutive tests performed at least 2 weeks apart, and a cardiac index of less than $2.2 \mathrm{~L} / \mathrm{min} / \mathrm{m}$ (Provencher et al 2006). Due to its similar mode of action, it is unlikely that patients like these will respond any better to other ERAs including ambrisentan. The FDA has approved ambrisentan for treatment of WHO functional class II or III patients, but not class IV. Treatment guidelines published by professional societies also suggest that PAH patients in functional class IV at initial evaluation or who progress to functional class IV during therapy are not good candidates for treatment with ambrisentan alone (Badesch et al 2004). Instead, these patients should be treated with prostacyclin infusion either alone or in combination with sildenafil or an ERA. Under these circumstances, ambrisentan would be an appropriate adjunct to prostacyclin infusion therapy.

\section{Combination therapy with ambrisentan}

Potential drug-drug interactions between ambrisentan and sildenafil or warfarin have been evaluated in healthy subjects. Pharmacokinetic parameters of ambrisentan and sildenafil were similar when administered as monotherapy or in combination. The pharmacokinetics of n-desmethylsildenafil, the active metabolite of sildenafil, were also unaffected by multiple doses of ambrisentan (Dufton et al 2006). The interaction of ambrisentan and warfarin was evaluated in 22 healthy volunteers, who were given a single 25 -mg oral dose of warfarin before and after 8 days of oral ambrisentan $10 \mathrm{mg}$ /day (Gerber 2006). Ambrisentan did not affect the Cmax or AUC of warfarin, although a small reduction in prothrombin time was observed $(-14.2 \%$; 95\% CI, $-16.6 \%$ to $-11.8 \%$ ). In both studies, ambrisentan was well tolerated and no safety concerns arose with the combination therapies. The lack of a pharmacodynamic effect of ambrisentan on warfarin metabolism has been confirmed in ambrisentan clinical trials to date.

The recognition that monotherapy for $\mathrm{PAH}$ with presently available therapies is often inadequate, has led investigators to consider combining multiple classes of pulmonary vasodilators (Humbert et al 2004a). The lack of identifiable adverse interactions between ambrisentan and sildenafil or prostacyclin make it well suited for future combination therapies in PAH. 


\section{Conclusion}

Ambrisentan appears to be a safe and efficacious treatment for PAH patients in WHO functional class II or III. At the present time, it is unclear if selective ERAs like ambrisentan offer any clinical advantages over non-selective ERAs or phosphodiesterase inhibitors. Improvements in pulmonary hemodynamics and exercise capacity with ambrisentan are similar to those achieved with other approved therapies for PAH. Ambrisentan does have a lower incidence of serum aminotransferase elevation than other ERAs and requires only once daily dosing. However, these advantages should be weighed against the limited long-term experience with this agent in treating PAH. More data are needed on the sustained efficacy and safety of ambrisentan during prolonged treatment of PAH, and on the effect of extended ambrisentan therapy on survival. In the meantime, its favorable efficacy and safety profile demonstrated in Phase II and III clinical trials and its ease of use suggest that ambrisentan will play an important role in the medical therapy for PAH and provide another therapeutic options to combat this challenging disease.

\section{Disclosures}

Dr Klinger participates in multicenter clinical trials that are supported by Gilead, Actelion and Pfizer, and has received speaking honoria and consulting fees from Actelion, United Therapeutics, and Encysive Pharmaceuticals.

\section{References}

Alberts GF, Peifley KA, Johns A, et al. 1994. Constitutive endothelin-1 overexpression promotes smooth muscle cell proliferation via an external autocrine loop. J Biol Chem, 269:10112-8.

Amberg W, Hergenroder S, Hillen H, et al. 1999. LU208075 and LU302146, two novel ETA-selective endothelin receptor antagonists: SAR of 3,3-diaryl propionic acid derivatives. International Conference on Endothelin, 6 October 10-13P.

Anand I, McMurray J, Cohn J, et al. 2004. Long-term effects of darusentan on left-ventricular remodelling and clinical outcomes in the EndothelinA Receptor Antagonist Trial in Heart Failure (EARTH): randomised, double-blind, placebo-controlled trial. Lancet, 364:347-54.

Badesch DB, Abman SH, Ahearn GS, et al. 2004. Medical therapy for pulmonary arterial hypertension: ACCP evidence-based clinical practice guidelines. Chest, 126:35S-62S.

Barst RJ, Langleben D, Frost A, et al. 2004. Sitaxsentan therapy for pulmonary arterial hypertension. Am J Respir Crit Care Med, 169:441-7.

Barst RJ, Langleben D, Badesch D, et al. 2006. Treatment of pulmonary arterial hypertension with the selective endothelin-A receptor antagonist sitaxsentan. J Am Coll Cardiol, 47:2049-56.

Battistini B, Berthiaume N, Kelland NF, et al. 2006. Profile of past and current clinical trials involving endothelin receptor antagonists: the novel “-sentan” class of drug. Exp Biol Med (Maywood), 231:653-95.

Bauer M, Wilkens H, Langer F, et al. 2002. Selective upregulation of endothelin B receptor gene expression in severe pulmonary hypertension. Circulation, 105:1034-6.
Bayes M, Rabasseda X, Prous JR. 2006. Gateways to clinical trials. Methods Find Exp Clin Pharmacol, 28:451-95.

Benza RL, Barst RJ, Galie N, et al. 2008. Sitaxsentan for the treatment of pulmonary arterial hypertension: a 1-year,prospective, open-label observation of outcome and survival. Chest, 134:775-82.

Billman GE. 2002, Ambrisentan (Myogen). Curr Opin Investig Drugs, 3:1483-6.

Black, SM, Mata-Greenwood E, Dettman RW, et al. 2003, Emergence of smooth muscle cell endothelin B-mediated vasoconstriction in lambs with experimental congenital heart disease and increased pulmonary blood flow. Circulation, 108:1646-54.

Bolli MH, Marfurt J, Grisostomi C, et al. 2004, Novel benzo[1,4]diazepin2-one derivatives as endothelin receptor antagonists. $J$ Med Chem, 47:2776-95

Boss C, Bolli M, Weller T. 2002. Endothelin receptor antagonists: structures, synthesis, selectivity and therapeutic applications. Curr Med Chem, 9:349-83.

Boulanger C, Luscher TF. 1990. Release of endothelin from the porcine aorta. Inhibition by endothelium-derived nitric oxide. J Clin Invest, 85:587-90.

Budhiraja R, Tuder RM, Hassoun PM. 2004. Endothelial dysfunction in pulmonary hypertension. Circulation, 109:159-65.

Cacoub P, Dorent R, Maistre, G, et al. 1993. Endothelin-1 in primary pulmonary hypertension and the Eisenmenger syndrome. Am J Cardiol, 71:448-50.

Cacoub P, Dorent R, Nataf P, et al. 1997. Endothelin-1 in the lungs of patients with pulmonary hypertension. Cardiovasc Res, 33:196-200.

Cernacek P, Franchi L, Dupuis J, et al. 1998. Radioreceptor assay of an endothelin A receptor antagonist in plasma and urine. Clin Chem, 44:1666-73

Chan SY, Loscalzo J. 2008. Pathogenic mechanisms of pulmonary arterial hypertension. J Mol Cell Cardiol, 44:14-30.

Cheng JW. 2008. Ambrisentan for the management of pulmonary arterial hypertension. Clin Ther, 30:825-33.

Clarke JG, Benjamin N, Larkin SW, et al. 1989. Endothelin is a potent longlasting vasoconstrictor in men. Am J Physiol, 257:H2033-5.

Clozel M. 2003. Effects of bosentan on cellular processes involved in pulmonary arterial hypertension: do they explain the long-term benefit? Ann Med, 35:605-13.

Clozel M, Breu V, Gray GA, et al. 1994. Phamacological characterization of bosentan, a new potent orally active nonpeptide endothelin receptor antagonist. J Pharmacol Exp Ther, 270:228-35.

Clozel M, Roux S. 2000. The pharmacology of endothelin and its antagonist bosentan. Ann Endocrinol (Paris), 61:75-9.

D'Orleans-Juste P, Labonte J, Bkaily G, et al. 2002. Function of the endothelin(B) receptor in cardiovascular physiology and pathophysiology. Pharmacol Ther, 95:221-38.

Davie N, Haleen S J, Upton PD, et al. 2002. ET(A) and ET(B) receptors modulate the proliferation of human pulmonary artery smooth muscle cells. Am J Respir Crit Care Med, 165:398-405.

De Nucci G, Thomas R, D’Orleans-Juste P, et al. 1988. Pressor effects of circulating endothelin are limited by its removal in the pulmonary circulation and by the release of prostacyclin and endothelium-derived relaxing factor. Proc Natl Acad Sci US A, 85:9797-800.

Dufton C, Gerber M, Yin O, et al. 2006. No clinically relevant pharmacokinetic interaction between ambrisentan and sildenafil. Chest, $130: 254 \mathrm{~S}$

Dupuis J. 2000. Endothelin receptor antagonists and their developing role in cardiovascular therapeutics. Can J Cardiol, 16:903-10.

Dupuis J, Goresky CA, Fournier A. 1996. Pulmonary clearance of circulating endothelin-1 in dogs in vivo: exclusive role of ETB receptors. $J$ Appl Physiol, 81:1510-5

Emori T, Hirata Y, Ohta K, et al. 1991. Cellular mechanism of endothelin-1 release by angiotensin and vasopressin. Hypertension, 18:165-70.

Emoto N, Yanagisawa M. 1995. Endothelin-converting enzyme-2 is a membrane-bound, phosphoramidon-sensitive metalloprotease with acidic pH optimum. J Biol Chem, 270:15262-8. 
Feger GI, Schilling L, Ehrenreich H, et al. 1997. Endothelium-dependent relaxation counteracting the contractile action of endothelin-1 is partly due to ETB receptor activation. Res Exp Med (Berl), 196:327-37.

FDA/CDER Letairis (ambrisentan tablets) Clinical Pharmacology. Biopharmaceutics Review 3:98-99. Accessed May 28 2008. URL:http://www. fda.gov/cder/foi/nda/2007/022081s000_ClinPharmR_P3.pdf .

Frantz RP, Robbins IM, Durst LA, et al. 2008. Endothelin-1 and BNP plasma levels predict survival in patients with pulmonary arterial hypertension. Amer J Respir Crit Care Med, 177:A535.

Galie N, Badesch D, Oudiz R, et al. 2005. Ambrisentan therapy for pulmonary arterial hypertension. J Am Coll Cardiol, 46:529-35.

Galie N, Beghetti M, Gatzoulis MA, et al. 2006. Bosentan therapy in patients with Eisenmenger syndrome: a multicenter, double-blind, randomized, placebo-controlled study. Circulation, 114:48-54.

Galie N, Keogh AM, Frost A, et al. 2005. Ambrisentan long-term safety and efficacy in pulmonary arterial hypertension-one year follow up. Proc Am Thorac Soc, 2:A299.

Galie N, Manes A, Branzi A. 2004. The endothelin system in pulmonary arterial hypertension. Cardiovasc Res, 61:227-37.

Galie N, Olschewski H, Oudiz RJ, et al. 2008. Ambrisentan for the treatment of pulmonary arterial hypertension: results of the ambrisentan in pulmonary arterial hypertension, randomized, double-blind, placebocontrolled, multicenter, efficacy (ARIES) study 1 and 2. Circulation, 117:3010-9.

Gerber MJ, Dufton C, Pentikis H, et al. 2006. Ambrisentan has no clinically relevant effect on the pharmacokinetics or pharmacodynamics of warfarin. Chest, 130:256S.

Gomberg-Maitland M, Olschewski H. 2008. Prostacyclin therapies for the treatment of pulmonary arterial hypertension. Eur Respir $J$, 31:891-901.

Granton J, Moric J. 2008. Pulmonary vasodilators - treating the right ventricle. Anesthesiol Clin, 26:337-53, vii.

Gray GA, Webb DJ. 1996. The endothelin system and its potential as a therapeutic target in cardiovascular disease. Pharmacol Ther, 72:109-48.

Greene S, Nunley K, Weber S, et al. 2006. ETA vs ETB receptor selectivity of endothelin-1 receptor antagonists in human myocardial membranes. $J$ Am Coll Cardiol, 47:307A.

Gregan B, Jurgensen J, Papsdorf G, et al. 2004. Ligand-dependent differences in the internalization of endothelin A and endothelin B receptor heterodimers. J Biol Chem, 279:27679-87.

Guarda E, Katwa LC, Myers PR, et al. 1993. Effects of endothelins on collagen turnover in cardiac fibroblasts. Cardiovasc Res, 27:2130-4.

Haynes WG, Webb DJ. 1992. Endothelin: a long-acting local constrictor hormone. Br J Hosp Med, 47:340-9.

Hopfner R. 1999. Sixth International Conference on Endothelin (ET-6), Montreal, Canada. Meeting Report IDDB; October 10-13.

Hu RM, Levin ER, Pedram A, et al. 1992 Atrial natriuretic peptide inhibits the production and secretion of endothelin from cultured endothelial cells. Mediation through the C receptor. $J$ Biol Chem, 267:17384-9.

Humbert M, Barst RJ, Robbins IM, et al. 2004a. Combination of bosentan with epoprostenol in pulmonary arterial hypertension: BREATHE-2. Eur Respir J, 24:353-9.

Humbert M, Sitbon O, Simonneau G. 2004b Treatment of pulmonary arterial hypertension. $N$ Engl J Med, 351:1425-36.

Inoue A, Yanagisawa M, Kimura S, et al. 1989 The human endothelin family: three structurally and pharmacologically distinct isopeptides predicted by three separate genes. Proc Natl Acad Sci U S A, 86:2863-7.

Jacobs A, Preston IR, Gomberg-Maitland M. 2006 Endothelin receptor antagonism in pulmonary arterial hypertension - a role for selective ET(A) inhibition? Curr Med Res Opin, 22:2567-74.

Janakidevi K, Fisher MA, Del Vecchio PJ, et al. 1992. Endothelin-1 stimulates DNA synthesis and proliferation of pulmonary artery smooth muscle cells. Am J Physiol, 263:C1295-301.

Jasmin JF, Lucas M, Cernacek P, et al. 2001. Effectiveness of a nonselective $\mathrm{ET}(\mathrm{A} / \mathrm{B})$ and a selective ET(A) antagonist in rats with monocrotalineinduced pulmonary hypertension. Circulation, 103:314-8.
Jeng AY, Mulder P, Kwan AL, et al. 2002. Nonpeptidic endothelinconverting enzyme inhibitors and their potential therapeutic applications. Can J Physiol Pharmacol, 80:440-9.

Jougasaki M, Larsen AM, Cataliotti A, et al. 2002. Cardiotrophin-1 stimulates endothelin-1 via gp130 in vascular endothelial cells. Peptides, 23:1441-7.

Klipper E, Levy N, Gilboa T, et al. 2006. Identification of a novel alternatively spliced variant endothelin converting enzyme-1 lacking a transmembrane domain. Exp Biol Med (Maywood), 231:723-8.

Langleben D. 2007. Endothelin receptor antagonists in the treatment of pulmonary arterial hypertension. Clin Chest Med, 28:117-25, viii.

Langleben D, Dupuis J, Langleben I, et al. 2006. Etiology-specific endothelin-1 clearance in human precapillary pulmonary hypertension. Chest, 129:689-95.

Levin ER. 1995. Endothelins. $N$ Engl J Med, 333:356-63.

Liu C, Chen J. 2006. Endothelin receptor antagonists for pulmonary arterial hypertension. Cochrane Database Syst Rev, 3, CD004434.

Love MP, McMurray JJ. 1996. Endothelin in chronic heart failure: current position and future prospects. Cardiovasc Res, 31:665-74.

Luscher TF, Barton M. 2000. Endothelins and endothelin receptor antagonists: therapeutic considerations for a novel class of cardiovascular drugs. Circulation, 102:2434-40.

Luscher TF, Enseleit F, Pacher R, et al. 2002. Hemodynamic and neurohumoral effects of selective endothelin A (ET(A)) receptor blockade in chronic heart failure: the Heart Failure ET(A) Receptor Blockade Trial (HEAT). Circulation, 106:2666-72.

MaClean MR, McCulloch KM, Baird M. 1995. Effects of pulmonary hypertension on vasoconstrictor responses to endothelin-1 and sarafotoxin S6C and on inherent tone in rat pulmonary arteries. $J$ Cardiovasc Pharmacol, 26:822-30.

Masaki T, Kimura S, Yanagisawa M, et al. 1991. Molecular and cellular mechanism of endothelin regulation. Implications for vascular function. Circulation, 84:1457-68.

Masaki T, Miwa S, Sawamura T, Ninomiya H, et al. 1999. Subcellular mechanisms of endothelin action in vascular system. Eur J Pharmacol, 375:133-8.

Matsui K, Takano Y, Yu ZX, et al. 2002. Immunohistochemical study of endothelin-1 and matrix metalloproteinases in plexogenic pulmonary arteriopathy. Pathol Res Pract, 198:403-12.

McCulloch KM, Docherty C, MaClean MR. 1998. Endothelin receptors mediating contraction of rat and human pulmonary resistance arteries: effect of chronic hypoxia in the rat. Br J Pharmacol, 123:1621-30.

McCulloch KM, MaClean MR. 1995. EndothelinB receptor-mediated contraction of human and rat pulmonary resistance arteries and the effect of pulmonary hypertension on endothelin responses in the rat. J Cardiovasc Pharmacol, 26(Suppl 3):S169-76.

McGoon M, Frost A, Oudiz R, et al. 2006. Ambrisentan rescue therapy in patients with pulmonary arterial hypertension who discontinued bosentan or sitaxsentan due to liver function abnormalities. Chest, $130: 254 \mathrm{~S}$

McGoon MD, Frost AE, Oudiz RJ, 2008. Ambrisentan therapy in patients with pulmonary arterial hypertension who discontinued bosentan or sitaxsentan due to liver function test abnormalities. Chest. [Epub ahead of print].

Meidan R, Klipper E, Gilboa T, et al. 2005. Endothelin-converting enzyme-1, abundance of isoforms a-d and identification of a novel alternatively spliced variant lacking a transmembrane domain. J Biol Chem, 280:40867-74.

Miwa S, Iwamuro Y, Zhang XF, et al. 1999. Ca2+ entry channels in rat thoracic aortic smooth muscle cells activated by endothelin-1. Jpn J Pharmacol, 80:281-8.

Morimoto H, Shimadzu H, Kushiyama E, et al. 2001. Potent and selective ET-A antagonists. 1. Syntheses and structure-activity relationships of N-(6-(2-(aryloxy)ethoxy)-4-pyrimidinyl)sulfonamide derivatives. $J$ Med Chem, 44:3355-68.

Motte S, McEntee K, Naeije R. 2006. Endothelin receptor antagonists. Pharmacol Ther, 110:386-414. 
Mullol J, Baraniuk JN, Logun C. 1996. Endothelin-1 induces GM-CSF, IL-6 and IL-8 but not G-CSF release from a human bronchial epithelial cell line (BEAS-2B). Neuropeptides, 30:551-6.

Nagaya N, Nishikimi T, Uematsu M, et al. 2000. Plasma brain natriuretic peptide as a prognostic indicator in patients with primary pulmonary hypertension. Circulation, 102:865-70.

Niwa Y, Nagata N, Oka M, et al. 2000. Production of nitric oxide from endothelial cells by 31-amino-acid-length endothelin-1, a novel vasoconstrictive product by human chymase. Life Sci, 67:1103-9.

Nootens M, Kaufmann E, Rector T, et al. 1995. Neurohormonal activation in patients with right ventricular failure from pulmonary hypertension: relation to hemodynamic variables and endothelin levels. J Am Coll Cardiol, 26:1581-5.

Ohlstein EH, Arleth A, Bryan H, et al. 1992. The selective endothelin ETA receptor antagonist BQ123 antagonizes endothelin-1-mediated mitogenesis. Eur J Pharmacol, 225:347-50.

Opgenorth TJ, Wu-Wong JR, Shiosaki K. 1992. Endothelin-converting enzymes. FASEB $J, 6: 2653-9$.

Opitz, CF, Ewert R, Kirch W, et al. 2008. Inhibition of endothelin receptors in the treatment of pulmonary arterial hypertension: does selectivity matter? Eur Heart J.

Pollock DM, Keith TL, Highsmith RF. 1995. Endothelin receptors and calcium signaling. FASEB J, 9:1196-204.

Prie S, Leung TK, Cernacek P, et al. 1997. The orally active ET(A) receptor antagonist (+)-(S)-2-(4,6-dimethoxy-pyrimidin-2-yloxy)3-methoxy-3,3-diphe nyl-propionic acid (LU 135252) prevents the development of pulmonary hypertension and endothelial metabolic dysfunction in monocrotaline-treated rats. $J$ Pharmacol Exp Ther, 282:1312-8.

Prins BA, Hu RM, Nazario B, et al. 1994. Prostaglandin E2 and prostacyclin inhibit the production and secretion of endothelin from cultured endothelial cells. J Biol Chem, 269:11938-44.

Provencher S, Sitbon O, Humbert M, et al. 2006. Long-term outcome with first-line bosentan therapy in idiopathic pulmonary arterial hypertension. Eur Heart J, 27:589-95.

Rich S, McLaughlin VV, 2003. Endothelin receptor blockers in cardiovascular disease. Circulation, 108:2184-90.

Riechers H, Albrecht HP, Amber W, et al. 1996. Discovery and optimization of a novel class of orally active nonpeptidic endothelin-A receptor antagonists. $J$ Med Chem, 39:2123-8.

Rubanyi GM, Polokoff MA. 1994. Endothelins: molecular biology, biochemistry, pharmacology, physiology, and pathophysiology. Pharmacol Rev, 46:325-415.

Rubin LJ, Badesch DB, Barst RJ. 2002. Bosentan therapy for pulmonary arterial hypertension. $N$ Engl J Med, 346:896-903.

Rubin LJ, Dufton C Gerber MJ. 2005. Ambrisentan for pulmonary arterial hypertension. Future Cardiol, 1:1-8.

Russell FD, Davenport AP. 1999. Secretory pathways in endothelin synthesis. Br J Pharmacol, 126:391-8.

Schiffrin EL. 2005. Vascular endothelin in hypertension. Vascul Pharmacol, 43:19-29.

Schmidt M, Kroger B, Jacob E, et al. 1994. Molecular characterization of human and bovine endothelin converting enzyme (ECE-1). FEBS Lett, 356:238-43.

Schroll S, Arzt M, Sebah D, et al. 2008. Effects of selective and unselective endothelin-receptor antagonists on prostacyclin synthase gene expression in experimental pulmonary hypertension. Scand J Clin Lab Invest, 68:270-6.
Seo B, Oemar BS, Siebenmann R, et al. 1994. Both ETA and ETB receptors mediate contraction to endothelin-1 in human blood vessels. Circulation, 89:1203-8.

Shi-Wen X, Chen Y, Denton CP, et al. 2004. Endothelin-1 promotes myofibroblast induction through the ETA receptor via a rac/phosphoinositide 3-kinase/Akt-dependent pathway and is essential for the enhanced contractile phenotype of fibrotic fibroblasts. Mol Biol Cell, 15:2707-19.

Shimada K, Takahashi M, Tanzawa K. 1994. Cloning and functional expression of endothelin-converting enzyme from rat endothelial cells. J Biol Chem, 269:18275-8.

Simonson MS, Dunn MJ. 1990. Cellular signaling by peptides of the endothelin gene family. FASEB J, 4:2989-3000.

Sirvio ML, Metsarinne K, Saijonmaa O, et al. 1990. Tissue distribution and half-life of 125I-endothelin in the rat: importance of pulmonary clearance. Biochem Biophys Res Commun, 167:1191-5.

Sitbon O, Gressin V, Speich R, et al. 2004. Bosentan for the treatment of human immunodeficiency virus-associated pulmonary arterial hypertension. Am J Respir Crit Care Med, 170:1212-7.

Stewart DJ, Levy RD, Cernacek P, et al. 1991. Increased plasma endothelin-1 in pulmonary hypertension: marker or mediator of disease? Ann Intern Med, 114:464-9.

Takahashi M, Matsushita Y, Iijima Y, et al. 1993. Purification and characterization of endothelin-converting enzyme from rat lung. $J$ Biol Chem, 268:21394-8.

Torres F. 2007. Systematic review of randomised, double-blind clinical trials of oral agents conducted in patients with pulmonary arterial hypertension. Int J Clin Pract, 61:1756-65.

Tuder RM, Cool CD, Yeager M, et al. 2001. The pathobiology of pulmonary hypertension. Endothelium. Clin Chest Med, 22:405-18.

Tuder RM, Marecki JC, Richter A, et al. 2007. Pathology of pulmonary hypertension. Clin Chest Med, 28:23-42, vii.

Valdenaire O, Lepailleur-Enouf D, Egidy G, et al. 1999. A fourth isoform of endothelin-converting enzyme (ECE-1) is generated from an additional promoter molecular cloning and characterization. Eur $J$ Biochem, 264:341-9.

Vatter H, Seifert V. 2006. Ambrisentan, a non-peptide endothelin receptor antagonist. Cardiovasc Drug Rev, 24:63-76.

Vatter H, Zimmermann M, Weyrauch E, et al. 2003. Cerebrovascular characterization of the novel nonpeptide endothelin-A receptor antagonist LU 208075. Clin Neuropharmacol, 26:73-83.

Verhaar MC, Strachan FE, Newby DE, et al. 1998. Endothelin-A receptor antagonist-mediated vasodilatation is attenuated by inhibition of nitric oxide synthesis and by endothelin-B receptor blockade. Circulation, 97:752-6.

Vierhapper H, Wagner O, Nowotny P, et al. 1990. Effect of endothelin-1 in man. Circulation, 81:1415-8.

Wagner OF, Christ G, Wojta J, et al. 1992. Polar secretion of endothelin-1 by cultured endothelial cells. J Biol Chem, 267:16066-8.

Xu D, Emoto N, Giaid A, et al. 1994. ECE-1: a membrane-bound metalloprotease that catalyzes the proteolytic activation of big endothelin-1. Cell, 78:473-85.

Yanagisawa H, Hammer RE, Richardson JA, et al. 2000. Disruption of ECE-1 and ECE-2 reveals a role for endothelin-converting enzyme-2 in murine cardiac development. J Clin Invest, 105:1373-82.

Yanagisawa M, Kurihara H, Kimura S, et al. 1988. A novel potent vasoconstrictor peptide produced by vascular endothelial cells. Nature, 332:411-5.

Yokokawa K, Tahara H, Kohno M, et al. 1993. Heparin regulates endothelin production through endothelium-derived nitric oxide in human endothelial cells. J Clin Invest, 92:2080-5. 